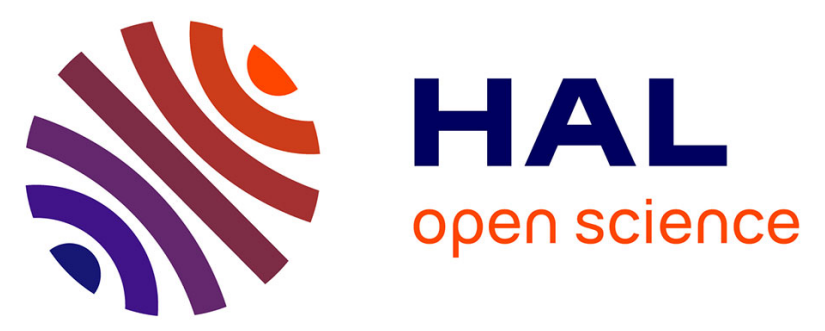

\title{
Global optimization of solar power tower systems using a Monte Carlo algorithm: Application to a redesign of the PS10 solar thermal power plant
}

\author{
Olivier Farges, Jean-Jacques Bézian, Mouna El-Hafi
}

\section{- To cite this version:}

Olivier Farges, Jean-Jacques Bézian, Mouna El-Hafi. Global optimization of solar power tower systems using a Monte Carlo algorithm: Application to a redesign of the PS10 solar thermal power plant. Renewable Energy, 2018, 119, pp.345-353. 10.1016/j.renene.2017.12.028 . hal-01660563

\section{HAL Id: hal-01660563 https://hal.science/hal-01660563}

Submitted on 26 Jan 2018

HAL is a multi-disciplinary open access archive for the deposit and dissemination of scientific research documents, whether they are published or not. The documents may come from teaching and research institutions in France or abroad, or from public or private research centers.
L'archive ouverte pluridisciplinaire $\mathbf{H A L}$, est destinée au dépôt et à la diffusion de documents scientifiques de niveau recherche, publiés ou non, émanant des établissements d'enseignement et de recherche français ou étrangers, des laboratoires publics ou privés. 


\title{
Global optimization of Solar Power Tower systems using a Monte Carlo algorithm: application to a redesign of the PS10 solar thermal power plant
}

\author{
O. Farges ${ }^{\mathrm{a}, \mathrm{b}, \mathrm{c}, *}$, J.J. Bézian ${ }^{\mathrm{c}}$, M. El Hafic ${ }^{\mathrm{c}}$ \\ ${ }^{a}$ Université de Lorraine, LEMTA, UMR 7563, Vandoeuvre-lès-Nancy, F-54500, France \\ ${ }^{b}$ CNRS, LEMTA, UMR 7563, Vandoeuvre-lès-Nancy, F-54500, France \\ ${ }^{c}$ Université Fédérale de Toulouse Midi-Pyrénées, Mines Albi, UMR CNRS 5302, Centre \\ RAPSODEE, Campus Jarlard, F-81013 Albi CT Cedex 09, France
}

\begin{abstract}
There is a need to enhance the performance of Solar Power Tower (SPT) systems in view of their significant capital costs. In this context, the preliminary design step is of great interest as improvements here can reduce the global cost. This paper presents an optimization method that approaches optimal SPT system design through the coupling of a Particle Swarm Optimization algorithm and a Monte Carlo algorithm, in order to assess both the yearly heliostat field optical efficiency and the thermal energy collected annually by an SPT system. This global optimization approach is then validated on a wellknown SPT system, ie the PS10 Solar Thermal Power plant. First, the direct model is compared to in-situ measurements and simulation results. Then, the PS10 heliostat field is redesigned using the optimization tool. This redesign step leads to an annual gain between $3.34 \%$ and $23.5 \%$ in terms of the thermal energy collected and up to about $9 \%$ in terms of the heliostat field optical efficiency from case to case.
\end{abstract}

Keywords: global optimization, solar power tower, lifetime performance, heliostat field layout

\section{Introduction}

A Solar Power Tower (SPT) system is a complex set composed of several different subsystems. It consists of a heliostat field, tower, receiver, heat transport system, power conversion system, plant control, optionally a thermal energy storage system, etc. The solar radiation is reflected and concentrated by the heliostat field onto a receiver. In the receiver, the concentrated energy is typically

\footnotetext{
*Principal Corresponding Author

Email address: olivier-farges@univ-lorraine.fr (O. Farges)
}

Preprint submitted to Elsevier

January 26, 2018 
used to generate heat to produce electricity through a thermodynamic cycle, to synthesize solar fuels or supply an industrial process. According to Kolb et al. (2007), a large proportion of the cost of an SPT is devoted to the heliostat field (up to 50\%). As a consequence, it is important to obtain an optimal design for this element. Heliostat fields have been widely researched since the 1970's, with several studies particularly dedicated to the optimization of this subsystem. Among the most recent developments, some interesting articles can be mentionned: (Pitz-Paal et al., 2011), (Carrizosa et al., 2015), (Wei et al., 2007), (Zhang et al., 2016) and (Ramos and Ramos, 2012) focuse on SPT optimization notably with global optimization methods ; (Noone et al., 2012), (Yao et al., 2015) and (Zhang et al., 2016) introduce innovative pattern for heliostat layout (in particular phyllotactic spiral) ; (Sánchez and Romero, 2006) propose a new quantity (yearly normalized energy surfaces) as the reference criterion for heliostat field generation. All the above-mentioned articles are based either on a computation of the power collected at one or more specifically chosen periods of the year, considered to be representative of the central receiver's overall performance, or on an approximation of the yearly performance of the solar plant, obtained by making significant assumptions. The choice of the Monte Carlo method to perform this study is an appropriate one, because it allows the simulation of complex geometries and becomes particularly useful when a large number of parameters are involved. This work therefore proposes the use of an efficient Monte Carlo algorithm that will provide an accurate estimation of both the yearly heliostat field optical efficiency and the yearly thermal energy collected (Farges et al., 2015). In order to select the best set of parameters to optimize the optical efficiency of the sub-system, this Monte Carlo algorithm is then coupled with a population-based stochastic algorithm, namely the Particle Swarm Optimization (PSO) algorithm (Kennedy and Eberhart, 1995). The section 2 is devoted to a brief description of the direct model to summarize the previous work by Farges et al. (2015) and to introduce the yearly heliostat field optical efficiency model. In section 3, all parameters taken into account during the optimization process are defined with their lower and upper bounds. In section 4, the optimization algorithm (PSO) is presented and its application to concentrated solar power plant design is discussed. The direct model and the global numerical tool are presented in section 5. This methodology is then applied to a test case: the PS10 Solar Thermal Power plant. The accuracy of the direct model is first compared to the existing system for validation purposes. Then a redesign of the PS10 heliostat field is carried out for various heliostat size classes and results for both systems (existing and redesigned) are compared.

\section{Description of the direct model}

This paper presents a new approach using a direct model based on Monte Carlo methods that is further combined with a stochastic optimization algo-

rithm. Achievement of an optimization task requires an efficient direct model of the target function called during the optimization process. 


\subsection{Modelling the yearly heliostat field optical efficiency}

In the present case, the direct model estimates the annual performance of an SPT. A model dealing with heliostat field optical efficiency commonly found in academic literature results in the product of instantaneaous optical efficiency terms related to optical behavour of heliostat fields. These terms deal with cosine effect, shading, blocking and spillage phenomena, interception efficiency, atmospheric attenuation and mirror reflectivity. Equation (1) presents this current formula (Noone et al., 2012), (Zhang et al., 2016), (Yao et al., 2015). This instantaneous optical efficiency makes it possible to calculate an annual optical efficiency.

$$
\eta=\eta_{c o s} \times \eta_{s b} \times \eta_{i t c} \times \eta_{a a} \times \eta_{r e f}
$$

This work introduces an optical efficiency model which differs from this commonly used model. Assuming that each sun ray has its self efficiency $\eta_{\text {ray }}$, this efficiency is equal to 1 when the ray hits the receiver and equal to 0 otherwise. This ray efficiency takes into account optical phenomena such as shading, blocking and spillage effect as well as interception efficiency. Then, a ray could:

- hit the receiver $\Rightarrow \eta_{\text {ray }}=1$

- be shaded (Shading effect) $\Rightarrow \eta_{\text {ray }}=0$

- be blocked (Blocking effect) $\Rightarrow \eta_{\text {ray }}=0$

- miss the receiver (Spillage effect) $\Rightarrow \eta_{\text {ray }}=0$

As a consequence, the instantaneous efficiency $\eta_{i}$ of a ray $i$ is presented in eq. (2):

$$
\eta_{i}=\eta_{\text {ray }} \times \eta_{\cos } \times \eta_{a a} \times \rho_{\mathcal{H}}
$$

with:

$\eta_{\text {cos }}$ Cosine efficiency: calculation of the cosine efficiency is straightforward using the Law of Reflection: it consists in a dot product between the incident direction of the sun ray $\boldsymbol{\omega}_{S}$ and the normal direction to the heliostat at the reflection location $\boldsymbol{n}_{h}$, as presented in eq. (3)

$\eta_{\boldsymbol{a} a}$ Atmospheric attenuation: sun radiation reflected by an heliostat towards the receiver is going to be impacted by radiative losses due to atmospheric attenuation. This attenuation is calculated as presented in eq. (4) with $d$ the distance between both ends of a sun ray (Schmitz et al., 2006).

$\rho_{h}$ Heliostats reflectivity

$$
\begin{aligned}
& \eta_{c o s}=\omega_{S} \cdot \boldsymbol{n}_{h} \\
& \eta_{a a}=\left\{\begin{array}{ll}
0.99321-0.0001176 d+1.97 \cdot 10^{-8} d^{2} & d \leq 1000 \mathrm{~m} \\
\exp (-0.0001106 d) & d>1000 \mathrm{~m}
\end{array}\right\}
\end{aligned}
$$


Thus, instantaneous heliostat field optical efficiency is obtained by averaging efficency of $N_{r}$ sun rays as presented in eq. (5). Nevertheless, it is much more interesting to focus on yearly heliostat field optical efficiency $\eta_{Y}$. Rays are sampled at any time of the year and yearly heliostat field optical efficiency is obtained by averaging efficency of $N_{r}$ sun rays as a fonction of time $\eta_{i}(t)$ as presented in eq. (6). This model tracks sun positions imitating a typical year's cycle. Heliostats are redirected according to the position of the sun in the sky, making the geometry of the SPT dynamic.

$$
\begin{gathered}
\eta=\frac{\sum_{i=1}^{N_{r}} \eta_{i}}{N_{r}} \\
\eta_{Y}=\frac{\sum_{i=1}^{N_{r}} \eta_{i}(t)}{N_{r}}
\end{gathered}
$$

\subsection{Modelling the yearly energy collected}

In addition to the yearly heliostat field optical efficiency, it is possible to evaluate, at the same time and without computational overtime, the yearly energy collected. From a radiative point of view, the evaluated quantity is the solar energy $E$ at the entrance of the receiver after concentration by the heliostat field. As presented in previous section, this model tracks sun positions. The quantity of interest is taken from the solar radiation data for a chosen area, coming from the Typical Meteorological Year (TMY) file. Being a function of the Direct Normal Irradiance (DNI), the yearly energy estimation requires a DNI value for each instant. This value is obtained from linear interpolation between consecutive TMY data, sampled every hour. As a fonction of both DNI and heliostat field optical efficiency, this model has the advantage of taking into account the unequal annual distribution of solar resource beside the optical efficiency model.

\subsection{MCST Monte Carlo algorithm}

This Monte Carlo algorithm, previously presented as the $\mathrm{MCST}^{1}$ algorithm (Farges et al., 2015), takes advantage of Monte Carlo integral formulation as outlined by de La Torre et al. (2014). An overview of the specific Monte Carlo algorithm, dealing with the sun's positions in the sky, is presented in fig. 1. Some dates are sampled using an importance sampling approach, then locations on the heliostat field where the sun rays are first reflected are uniformly sampled, after which the algorithm follows the behaviour of the rays in the SPT, ie computes reflections until each ray hits the final receiver or is lost. The MCST algorithm is thoroughly explained in (de La Torre et al., 2014), so it was decided not to go into detail here but only to reintroduce this algorithm with the addition of the yearly heliostat field optical efficiency estimation:

\footnotetext{
${ }^{1}$ MCST : Monte Carlo Sun Tracking
} 
(1) A DNI is uniformly sampled over the lifetime period according to $p_{\boldsymbol{\tau}}(t)$ and the corresponding one-hour time-integral is retained

(2) A location $\boldsymbol{r}_{1}$ is uniformly sampled on the reflective surface of the whole heliostat field $\mathcal{H}^{+}$of surface $S_{\mathcal{H}^{+}}$

(3) A direction $\boldsymbol{\omega}_{S}$ is uniformly sampled within the solar cone $\boldsymbol{\Omega}_{S}$ of angular radius $\theta_{S}$.

(4) An effective normal vector $\boldsymbol{n}_{h}$ is sampled around the ideal normal vector $\boldsymbol{n}_{1}$ at $\boldsymbol{r}_{1}$ representing reflection and pointing out imperfections. $\boldsymbol{\omega}_{1}$ corresponds to the specular reflection of $-\boldsymbol{\omega}_{S}$ by a surface normal to $\boldsymbol{n}_{h}$

(5) $\boldsymbol{r}_{0}$ is defined as the first intersection with a solid surface of the ray starting at $\boldsymbol{r}_{1}$ in the direction $\boldsymbol{\omega}_{S}$

(a) If $\boldsymbol{r}_{0}$ belongs to a heliostat surface $\mathcal{H}$ or to the receiver $\mathcal{R}$, a shading effect appears and Monte Carlo weights are $\hat{w}_{\eta_{Y}}=0$ and $\hat{w}_{E}=0$;

(b) If $\boldsymbol{r}_{0}$ doesn't exist (or is at the sun), the location $\boldsymbol{r}_{2}$ is defined as the first intersection with a solid surface of the ray starting at $\boldsymbol{r}_{1}$ in the direction $\boldsymbol{\omega}_{1}$

(i) If $\boldsymbol{r}_{2}$ belongs to something other than the receiver $\mathcal{R}$, there is a blocking effect and Monte Carlo weights are $\hat{w}_{\eta_{Y}}=0$ and $\hat{w}_{E}=0$;

(ii) If $\boldsymbol{r}_{2}$ does not exist there is a spillage effect and Monte Carlo weights are $\hat{w}_{\eta_{Y}}=0$ and $\hat{w}_{E}=0$;

(iii) If $\boldsymbol{r}_{2}$ belongs to the receiver $\mathcal{R}$, Monte Carlo weights are $\hat{w}_{\eta_{Y}}=$ $\frac{\rho_{h} \times \eta_{\cos }(t) \times \eta_{a a}(t)}{p_{\boldsymbol{\tau}}(t)}$ and $\hat{w}_{E}=\hat{w}_{\eta_{Y}} \times D N I(t) \times S_{\mathcal{H}^{+}}$

The related integral formulation is recalled in eq. (7):

$$
\begin{aligned}
\left(\eta_{Y}, E\right) & =\int_{\text {Lifetime }} p_{\boldsymbol{\tau}}(t) \mathrm{d} t \int_{\mathcal{D}_{\mathcal{H}}^{+}} p_{\boldsymbol{R}_{1}}\left(\boldsymbol{r}_{1}\right) \mathrm{d} \boldsymbol{r} \\
\int_{\mathcal{D}_{\boldsymbol{\Omega}_{S}}(t)} & p_{\boldsymbol{\Omega}_{S}(t)}\left(\boldsymbol{\omega}_{S}(t)\right) \mathrm{d} \boldsymbol{\omega} \int_{\mathcal{D}_{\boldsymbol{N}_{h}}} p_{\boldsymbol{N}_{h}}\left(\boldsymbol{n}_{h} \mid \boldsymbol{\omega}_{S}(t) ; b\right) \mathrm{d} \boldsymbol{n}\left(\hat{w}_{\eta_{Y}}(t), \hat{w}_{E}(t)\right)
\end{aligned}
$$

with time-dependent probability density functions

$$
\begin{aligned}
& p_{\boldsymbol{\Omega}_{S}(t)}=\frac{1}{\int_{\boldsymbol{\Omega}_{S}(t)} \mathrm{d} \boldsymbol{\omega}_{S}(t)}=\frac{1}{2 \pi\left(1-\cos \theta_{S}(t)\right)} \\
& p_{\boldsymbol{N}_{h}}\left(\boldsymbol{n}_{h} \mid \boldsymbol{\omega}_{S}(t) ; b\right)=\frac{\left(1+\frac{1}{b}\right) \times\left(\boldsymbol{n}_{h} \cdot \boldsymbol{n}_{1}\right)^{1+\frac{1}{b}}}{2 \pi \times\left(1-\cos ^{2+\frac{1}{b}}\left(\frac{\pi}{4}-\frac{1}{2} \times \arccos \left(\boldsymbol{\omega}_{S}(t) \cdot \boldsymbol{n}_{1}\right)\right)\right)}(9) \\
& p_{\boldsymbol{\tau}}(t)=\frac{D N I(t)}{\int_{\text {Lifetime }}} \operatorname{DNI(t)\mathrm {d}t}
\end{aligned}
$$


and Monte Carlo weights

$$
\begin{aligned}
& \hat{w}_{\eta_{Y}}(t)=\left\{\begin{array}{l}
\mathbf{H}\left(\boldsymbol{r}_{0} \in \mathcal{H} \cup \mathcal{R}\right) \times 0 \\
+\mathbf{H}\left(\boldsymbol{r}_{0} \notin \mathcal{H} \cup \mathcal{R}\right) \times\left\{\begin{array}{l}
\mathbf{H}\left(\boldsymbol{r}_{2} \notin \mathcal{R}\right) \times 0 \\
+\mathbf{H}\left(\boldsymbol{r}_{2} \in \mathcal{R}\right) \times \frac{\rho_{h} \times \eta_{\cos }(t) \times \eta_{a a}(t)}{p_{\boldsymbol{\tau}}(t)}
\end{array}\right\}
\end{array}\right\}(11) \\
& \hat{w}_{E}(t)=\hat{w}_{\eta_{Y}}(t) \times D N I(t) \times S_{\mathcal{H}^{+}}
\end{aligned}
$$

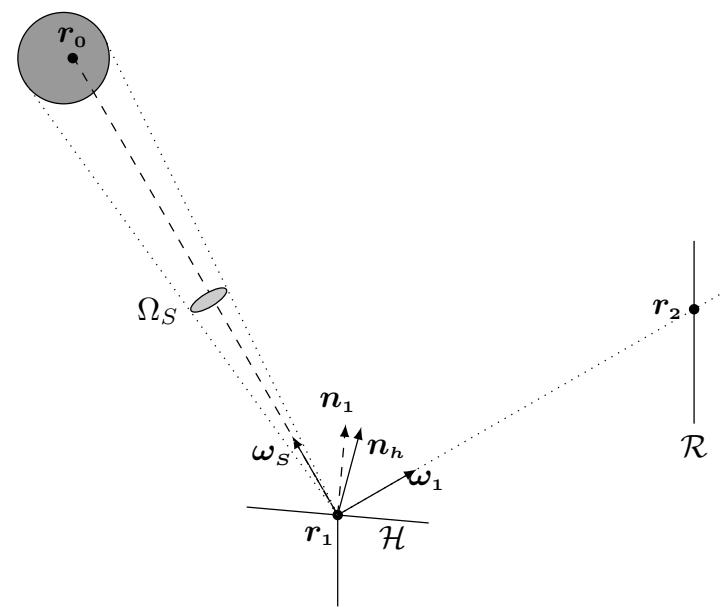

Figure 1: Schematic representation of the ray tracing process on a Solar Power Tower system with MCST

\subsection{A specific computing framework}

The direct model is implemented in the numerical framework EDStaR (de La Torre et al., 2014). This tool yields the practical implementation of a Monte Carlo algorithm for the radiative heat transfer model, making use of an integral formulation, and takes into consideration zero-variance approaches and sensitivity estimation as presented by Hoogenboom (2008) and Roger et al. (2005). Taking advantage of advanced rendering techniques developed by the computer graphics community, it can manage complex geometries with the use of the numerical library PBRT (Physically Based Rendering Techniques) (Pharr and Humphreys, 2010). It benefits from all the modern possibilities of computing such as massive parallelization and acceleration of ray tracing in a complex geometry. Different solar applications have already been simulated with this tool (de La Torre et al., 2014). EDStaR permits very efficient implementation of the direct model. With this tool, updating of the geometry is performed quickly and a simulation process can be achieved very rapidly, as presented in section 5.2. 


\section{Optimization}

This section presents the parameters of the optimization tool dedicated to the design of Solar Power Tower systems. This tool couples the Monte Carlo algorithm presented in section 2.3 with an optimization method. The numerical code deals with several parameters defining the SPT geometry, such as tower size, receiver size, heliostat shape and size, field layout, etc. All these parameters need to be taken into account by any target function which results in a complex mix of opposite effect specifications.

\subsection{Target function and parameters}

The direct model estimates both the yearly heliostat field optical efficiency and the yearly thermal energy collected by an SPT. Thus, these two values can represent the target function of the optimization process. In both cases, the chosen target function $f_{t}$ is influenced by several parameters defining the heliostat field and the tower of an SPT. A well-known geometrical pattern has been chosen to design the heliostat field: a radial staggered layout. The MUEEN method (Siala and Elayeb, 2001) is then implemented. This graphical method, consisting of a no-blocking radial staggered layout, is an iterative algorithm which adds a heliostat to the field until a regulatory limit is reached. This layout is based on groups of uniform heliostats. According to land occupation, a new group will be created in order to cover the available space. This specific function standardizes heliostat shapes: as each heliostat is represented as a curvated mirror, this curvature will be set for a whole group. The heliostat field is then formed by a number $N_{G}$ of heliostat groups of the same shape. This characteristic should lead to a reduction in the cost of the heliostat field. Likewise, with a view to both economy and optical efficiency, the size of the heliostat is also standardized. As regards the tower and the receiver, optimization parameters are mainly size parameters. Thus, the design parameters consist of:

- The width $w_{h}$ and height $h_{h}$ of the heliostats

- The width $w_{r}$ and height $h_{r}$ of the receiver

- The tilt angle of the receiver $\alpha_{r}$

- The height of the tower $H_{t}$

The design of an SPT is subject to several constraints. As a consequence, lower and upper bounds restrict free parameters. The aim of optimization is to maximize the target function $f_{t}$ dealing with these parameters. To identify the most suitable method, the particularities of the target function $f_{t}$ need to be investigated. Derivatives to parameters that modify the domain of integration cannot easily be obtained by the Monte Carlo method, as demonstrated by Roger et al. (2004). As a consequence, gradient-based methods cannot be applied efficiently in this case. Moreover, the non-smooth behaviour of the target function $f_{t}$ can be deduced intuitively, given the complexity of the whole system. Due to its non-smooth behaviour, the target function $f_{t}$ may have many local optima. It 
seems clear that global optimization methods are a suitable solution to investigate this kind of issue. Other work on SPT optimization has already analysed this possibility (Pitz-Paal et al., 2011), (Ramos and Ramos, 2012), (Carrizosa et al., 2015). This Monte Carlo based direct model is then coupled with a particle swarm optimizer (PSO) in order to achieve SPT optimal design.

\section{Stochastic optimization with PSO}

Many optimization approaches could be applied to the direct model introduced above. Among all these existing optimization methods, a stochastic particle swarm optimizer (PSO) algorithm is selected. There are several reasons for this, one being that it has been proven by Wetter and Wright (2004) that PSO is an efficient optimization method when dealing with non-smooth simulationbased optimization. Moreover, a particle swarm optimization algorithm, as a zero order optimization method, does not need to have derivatives with respect to one of the free parameters. Furthermore, PSO is a stochastic method and thus allows us to find the global optimum among all the local optima.

\subsection{The standard PSO algorithm}

This well-known population-based optimization method was first introduced by Kennedy and Eberhart (1995). According to this algorithm, each particle $i$ of the swarm has, at iteration $k$, a position $x_{i}^{k}$ in the search space, a velocity $v_{i}^{k}$ and a personal best position $p_{i}$. This personal best position corresponds to the $x_{i}$ maximizing the target function $f_{t}$. Additionally, the algorithm considers $g$, which is the global best position, i.e. among the particles of the swarm, the position of the one giving the highest target function. At iteration $k+1$, each particle position $x_{i}^{k+1}$ is updated with its previous position $x_{i}^{k}$ and its updated velocity $v_{i}^{k+1}$, as presented in Eqs. eqs. (13) and (14). The 2 numbers $r_{1}$ and $r_{2}$ are random numbers uniformly sampled in $[0,1]$ and used to effect the stochastic nature of the algorithm. The weight inertia $w$ is used to control the convergence behaviour of the PSO. The coefficients $c_{1}$ and $c_{2}$ control how far a particle will move in the search space in a single iteration. $c_{1}$ leads the individual behaviour of the particle whereas $c_{2}$ leads its social behaviour ${ }^{2}$. In addition, a velocity clamping is set with a maximum velocity gain $v_{\max }$ defined by $\left|v_{\max }\right|=k \times\left(x_{\max }-x_{\min }\right) / 2$ with $k$ a user-supplied velocity clamping factor fixed to 0.1 .

$$
\begin{aligned}
& v_{i}^{k+1}=w \times v_{i}^{k}+c_{1} \times r_{1} \times\left(p_{i}-x_{i}^{k}\right)+c_{2} \times r_{2} \times\left(g-x_{i}^{k}\right) \\
& x_{i}^{k+1}=x_{i}^{k}+v_{i}^{k+1}
\end{aligned}
$$

\footnotetext{
${ }^{2}$ As this work is not focused on PSO performance, set values for $c_{1}$ and $c_{2}$ parameters are determined in accordance with PSO basic principles: $c_{1}=c_{2}=1$
} 
Each particle generated by the PSO (i.e. each generated SPT system geometry described with a set of parameters) is evaluated with the direct model. Simulation results are used to establish particle performance, as they are the inputs of the target function $f_{t}$.

\section{Results}

In order to validate our method, an existing Central Receiver System is studied. PS10, the $11 \mathrm{MW}_{\text {e }}$ power plant, has been the subject of several studies and its main interest is that a considerable amount of data is available, notably proposed by Noone et al. (2012), Osuna et al. (2004) and Yao et al. (2015).

\subsection{The PS10 solar thermal power plant test case}

The PS10 Solar Power Plant is the world's first commercial concentrated solar tower power plant. This plant is located near Seville, in Andalusia, Spain. PS10 characteristics are presented in several scientific publications (Noone et al., 2012) (Osuna et al., 2004). The heliostat field consists of 624 heliostats following a radial staggered layout. Each heliostat has a surface measuring roughly $121^{2} \mathrm{~m}$ concentrating sun rays to the receiver. This solar receiver is placed on the top of a $115 \mathrm{~m}$ high tower and feeds a steam turbine. This power plant is designed to achieve a yearly production of $23 \mathrm{GW} \mathrm{h}_{\mathrm{e}}$ and about $95 \mathrm{GW} \mathrm{h}$ th $($ Osuna et al., 2006). The characteristic parameters of this solar power plant are summarized in table 1 and the solar field is depicted in fig. 2.

\subsection{Application of the direct model with PS10 specifications}

The example of application is the existing PS10 solar thermal power plant. The original PS10 heliostat field is accurately reproduced using available data, particularly concerning the heliostat coordinates. Appropriate irradiance data are obtained, as explained in section 2.2, from a Typical Meteorological Year file concerning Seville weather data (Blair et al., 2014). Achieving this simulation process took less than a minute for 50000 realizations on a laptop computer $^{3}$. The resulting yearly thermal energy at the entrance of the collector is $89.80 \pm 0.11 \mathrm{GW} \mathrm{h}_{\text {th }}$ which corresponds to the capacity of the PS10 SPT: $95 \mathrm{GW} \mathrm{h}_{\text {th }}$ in (Osuna et al., 2006). The yearly optical efficiency is also computed, leading to a consistent value: $\eta_{Y}=0.632$. This value is very closed to the yearly optical efficiency obtained with WinDELSOL1.0: $\eta_{Y}=0.6401$ (Noone et al., 2012). It can be concluded that the model is accurate, taking into account the significant variation that can appear between data for a typical meteorological year and the real weather conditions.

\footnotetext{
${ }^{3}$ The computation time is given for a desktop PC with AMD Phenom II X6 1055T 2.8 GHz and 12 Go RAM.
} 


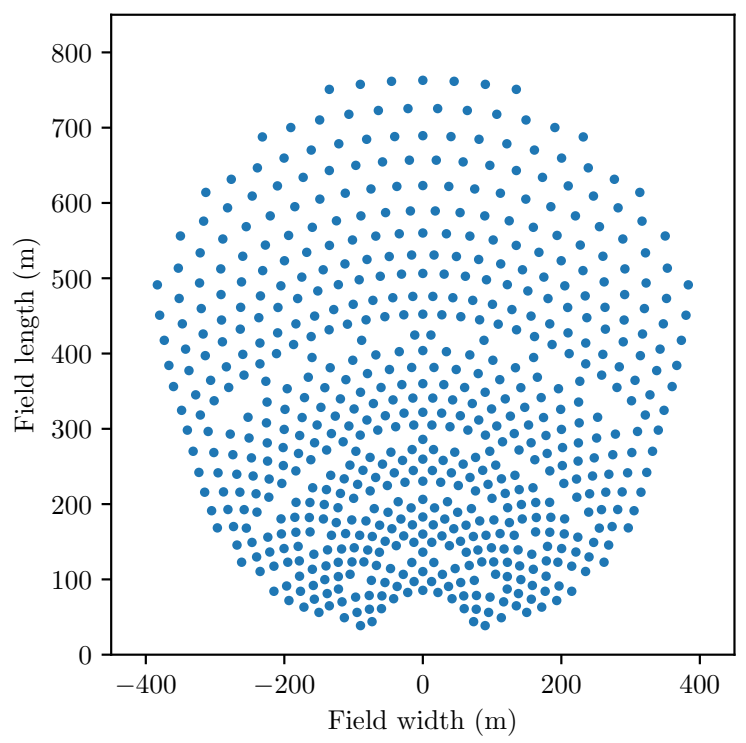

Figure 2: Original PS10 solar field

\subsection{Redesign of PS10}

In order to redesign the PS10 heliostat field, some assumptions are made. Firstly, the present work focused on yearly thermal energy and yearly heliostat field optical efficiency: this optimization process did not take into account cost criteria. A constraint is set on the land surface area according to the PS10 specifications. The optimized heliostat field layouts are obtained by optimizing only heliostat geometry. Hence, the tower and the receiver characteristics are kept constant. As previously discussed, the heliostat field pattern is defined according to the MUEEN method (Siala and Elayeb, 2001). As a consequence, the parameters used for the optimization are width and height of heliostats. Several cases are studied, divided into 6 heliostats size groups, for both quantities of interest, ie yearly thermal energy $E$ and yearly heliostat field optical efficiency $\eta_{Y}$. This breakdown allows to identify several optimal heliostat fields with comparable levels of performance. This leads to 12 redesigned heliostat fields, as presented in table 2 which set out lower and upper bounds of considered parameters. PSO parameters used for optimization processes are presented in table 3 . Using these assumptions, the 12 optimization processes are run. Tables 4 and 5 summarize the overall results. Table 4 provides outcomes related to heliostat fields geometry parameters and table 5 presents performance for each case in terms of yearly energy and yearly optical efficiency. The amount of yearly thermal energy collected at the entrance of the receiver increased from $89.8 \mathrm{GW} \mathrm{h}_{\text {th }}$ to at most $110.9 \mathrm{GW} \mathrm{h}_{\text {th }}$, leading to a net increase of about $23.5 \%$ 
(SPT Ref. $A_{1}$ ). The yearly heliostat field optical efficiency increased from 0.632 to at most 0.69 , leading to a net increase of about $9.2 \%$ (SPT Ref. $B_{2}$ ). One can notice a significant increase of the optimized quantities: between $12.5 \%$ and $23.5 \%$ towards yearly energy and between $7.59 \%$ and $9.2 \%$ with regards to yearly optical efficiency. When focusing on the total mirror surface (fig. 3) to analyse table 5 , it appears that for $f_{t}=E$ cases, the yearly energy increase observed for each case is mainly due to a mirror surface increase like in case $A_{1}$. On the other hand, it implies a negative impact on the yearly optical efficiency $(-2.37 \%)$ On the contrary, for $f_{t}=\eta_{Y}$ cases, with a mirror surface in the same range as the original PS10 heliostat field, the yearly heliostat field optical efficiency is significantly increased because of an improved layout: the localisation of each heliostat has been designed to be optimal.

Results on yearly energy are shown on fig. 4. A global trend can be seen: no matter the objective function, the amount of thermal energy collected by an optimized SPT increased when heliostat size decreased. This is mainly because of an improved floor area occupation. This trend is notably observable at the Ivanpah solar electric generating system (BrightSource, 2015), where each heliostat measures an area of $15 \mathrm{~m}^{2}$. The opposite effect can be seen on fig. 5 when the optimized quantity is the yearly energy $E$ : the yearly optical efficiency is adversely affected by the heliostat size decreasing. On the contrary, when the optimized quantity is the yearly heliostat field optical efficiency $\eta_{Y}$, fig. 5 shows a constant trend independently of size variations. Optimized heliostat fields layouts are presented on figs. 6 and 7. A comparison between these heliostat fields and the original one, presented on fig. 2 reveales high discrepancies. It is remarkable that the land cover of the original heliostat field is more uniform whereas optimized layouts appeared more scattered. Moreover, the redesigned heliostat field benefits from the group-based behaviour of the MUEEN method: there are only a limited number of heliostat geometries for the whole field: from 4 groups to 7 groups. In terms of optical efficiency, this leads to a non-negligible standardization effect. The computational time devoted to one optimization routine is approximately $4 \mathrm{~h}$ on a laptop computer ${ }^{4}$.

\section{Conclusion}

This work presents a new tool to optimally design solar power tower systems. The aim of the optimization step, based on a Particle Swarm Optimization algorithm, is to maximize the yearly thermal energy collected at the entrance of a solar receiver and/or the yearly heliostat field optical efficiency, using an efficient Monte Carlo algorithm. These quantities could easily be estimated for the solar plant lifetime (ie 50 years) rather than for a single year, as presented here. In doing so, ageing effects of components and potential climate change for the considered location could be studied. The PS10 solar thermal power

\footnotetext{
${ }^{4}$ The computation time is given for a desktop PC with AMD Phenom II X6 1055T $2.8 \mathrm{GHz}$ and 12 Go RAM.
} 


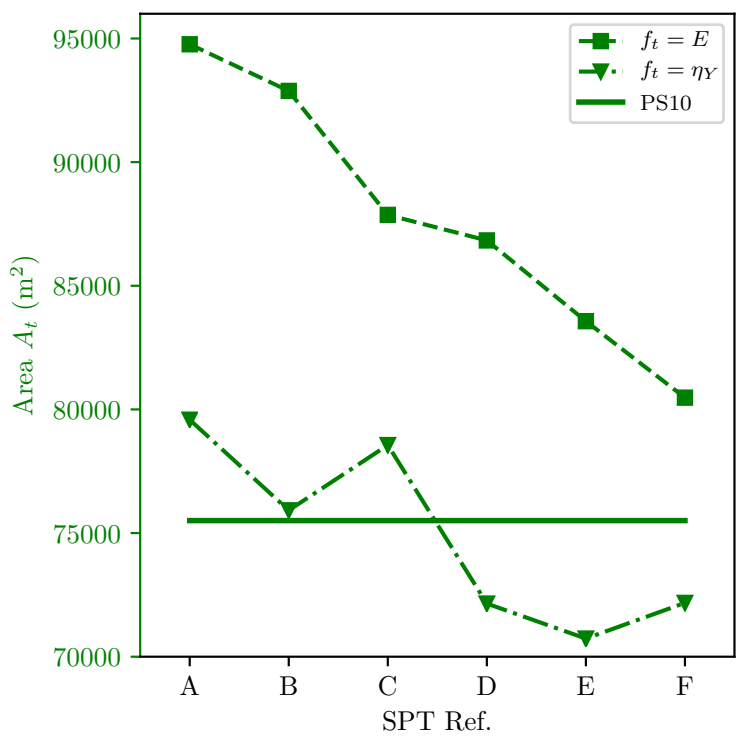

Figure 3: Mirror surface for each case

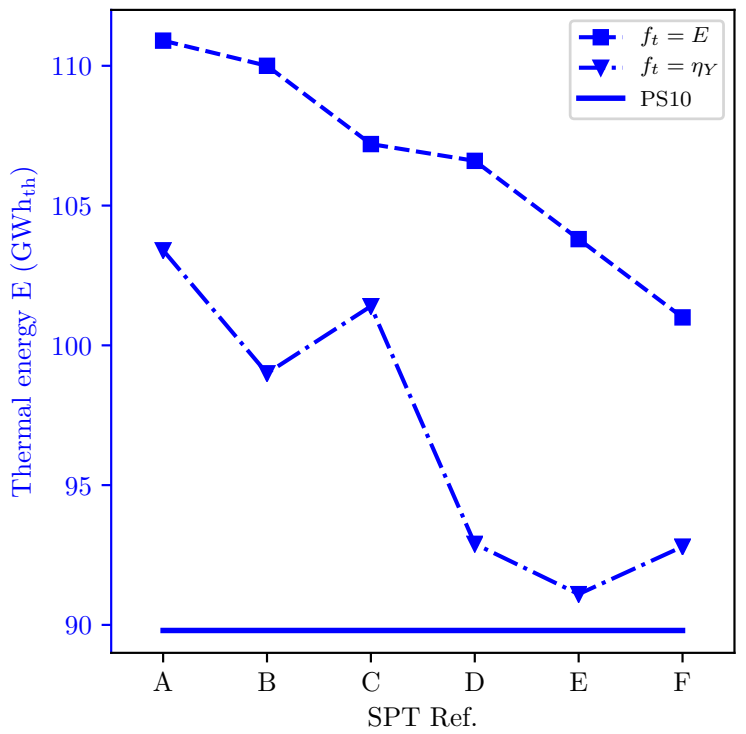

Figure 4: Yearly thermal energy collected for each case 


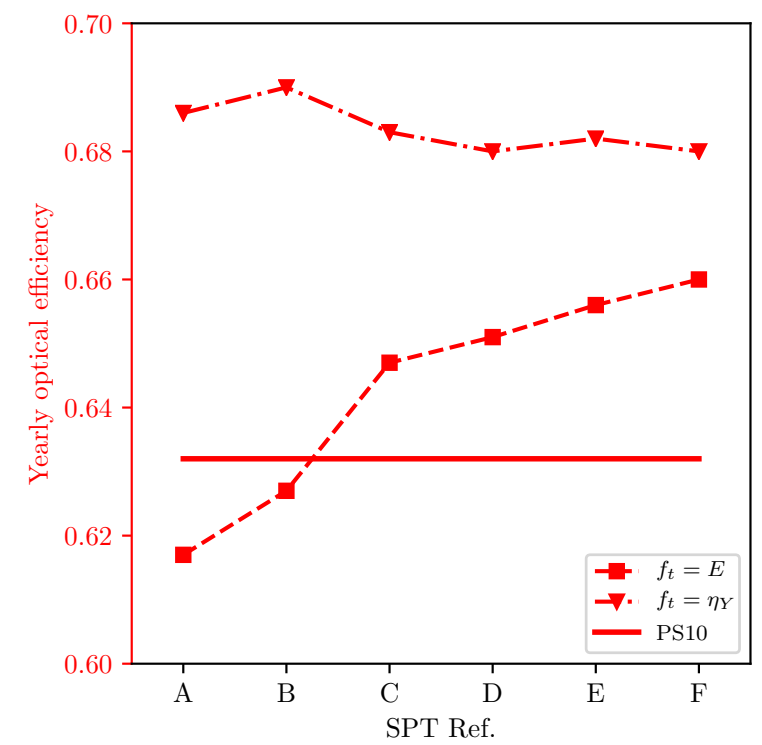

Figure 5: Yearly heliostat field optical efficiency for each case

plant is used as a validation case for the direct model using the Monte Carlo method. This power plant is also redesigned using this methodology leading to a significant improvement, between $3.34 \%$ and $23.5 \%$ in terms of yearly thermal energy collected and up to about $9 \%$ in terms of yearly heliostat field optical efficiency. These significant gains confirms our expectation that considering accurate time-integrated performance of an SPT system during the design step leads to remarkable improvement. A geometrical pattern is used for the redesign step. Based on a radial staggered layout (MUEEN method), this pattern is particularly restrictive when considering the blocking effect. Implementation of a more flexible pattern should increase the SPT performance. However, this pattern allows some standardization of heliostat shapes. In forthcoming work, the direct model will integrate the estimation of the final output, ie electricity production, and the SPT system investment cost, so as to optimize the Levelized Cost of Energy (LCOE) rather than the yearly thermal energy collected and/or the yearly heliostat field optical efficiency.

\section{References}

G. J. Kolb, S. A. Jones, M. W. Donnelly, D. Gorman, R. Thomas, R. Davenport, R. Lumia, Heliostat cost reduction study, Tech. Rep., 2007.

R. Pitz-Paal, N. B. Botero, A. Steinfeld, Heliostat field layout optimization 

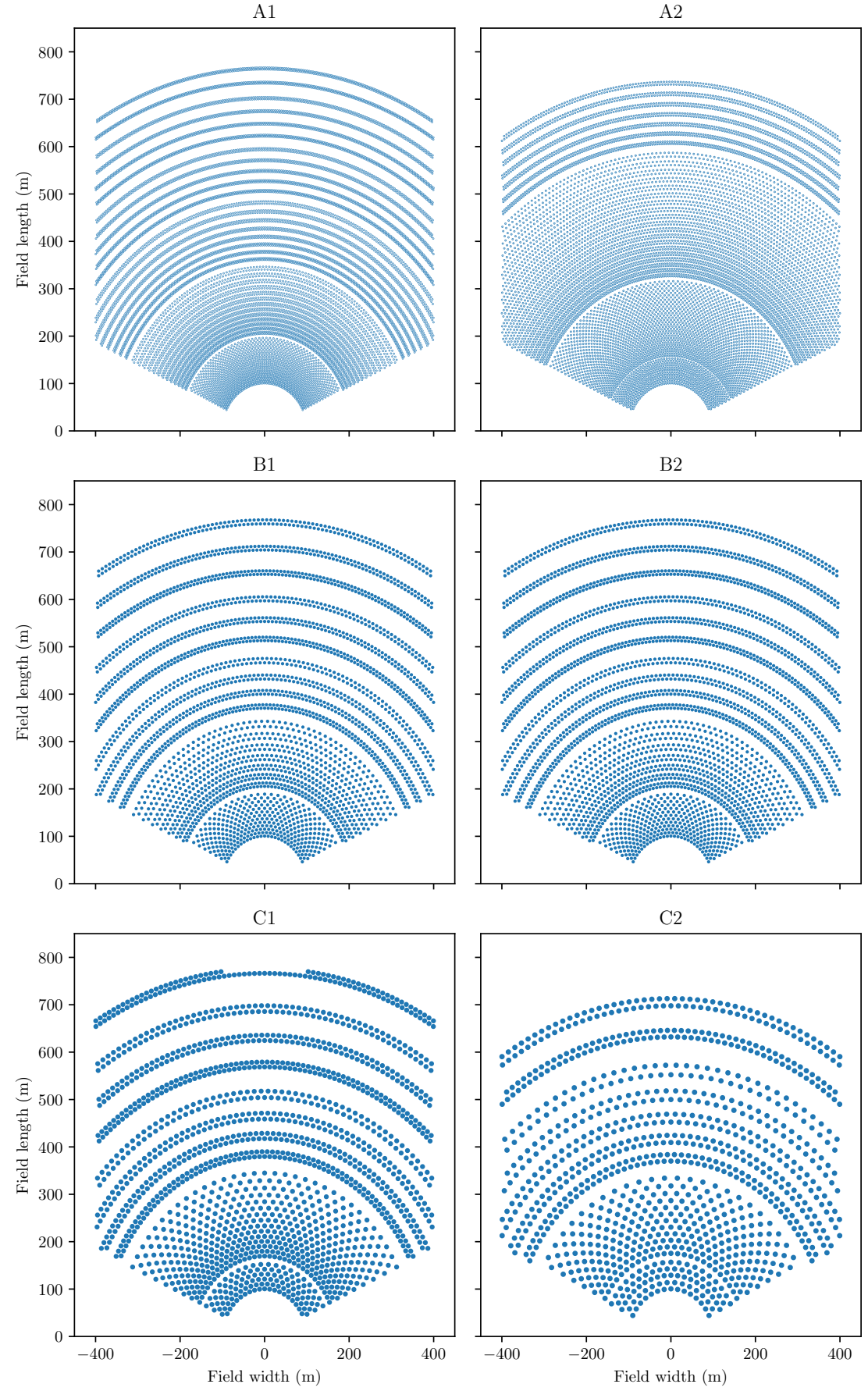

Figure 6: Redesigned PS10 solar fields (1) 

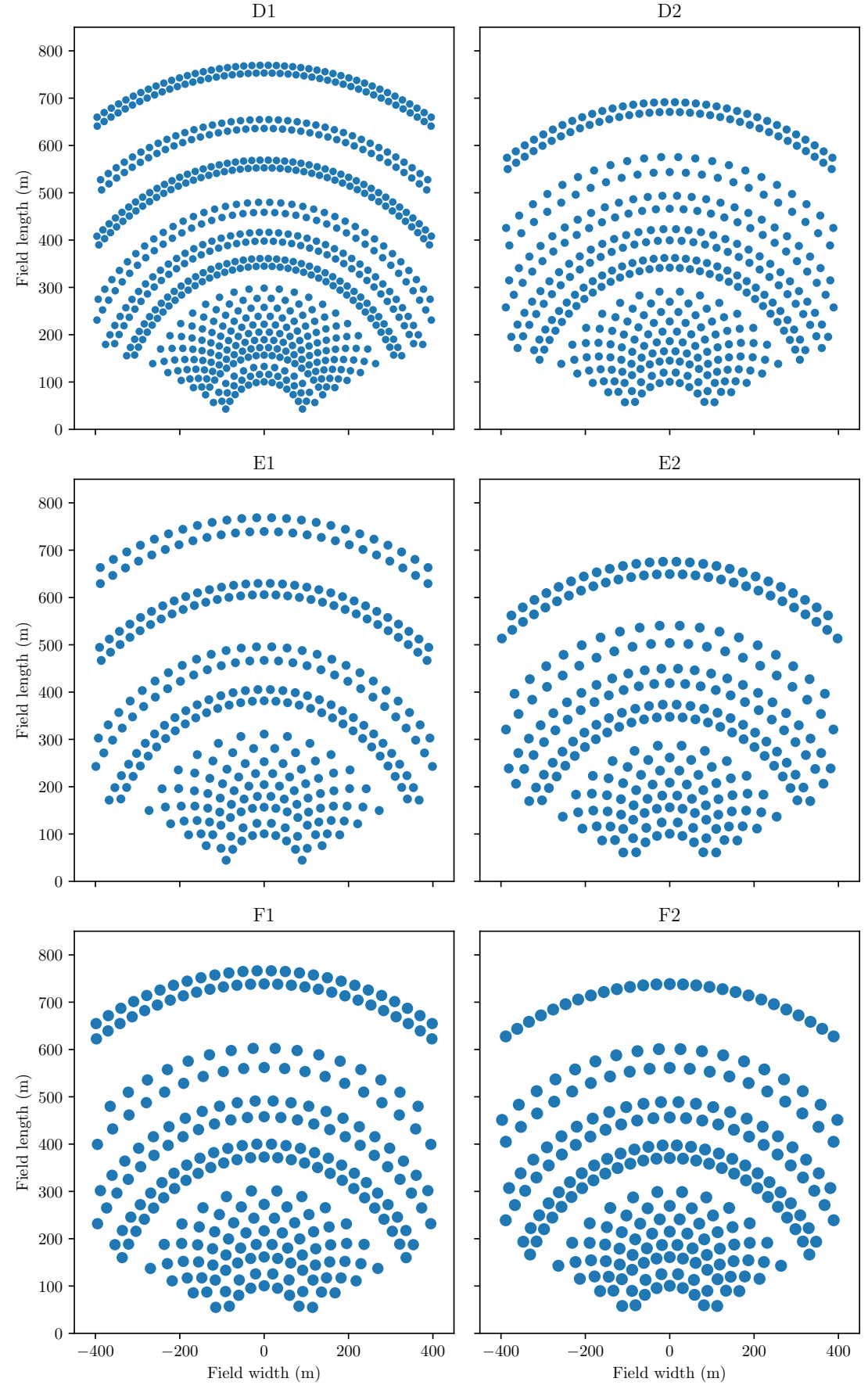

Figure 7: Redesigned PS10 solar fields (2) 
for high-temperature solar thermochemical processing, Solar Energy 85 (2) (2011) 334-343.

E. Carrizosa, C. Domínguez-Bravo, E. Fernández-Cara, M. Quero, A heuristic method for simultaneous tower and pattern-free field optimization on solar power systems, Computers \& Operations Research 57 (2015) 109-122.

X. Wei, Z. Lu, Z. Lin, H. Zhang, Z. Ni, Optimization procedure for design of heliostat field layout of a 1MWe solar tower thermal power plant, in: SPIE, vol. 6841, 684119, 2007.

M. Zhang, L. Yang, C. Xu, X. Du, An efficient code to optimize the heliostat field and comparisons between the biomimetic spiral and staggered layout, Renewable Energy 87, Part 1 (2016) 720 - 730, ISSN 0960-1481, doi: bibinfo\{doi\}\{http://dx.doi.org/10.1016/j.renene.2015.11.015\}, URL http: //www.sciencedirect.com/science/article/pii/S0960148115304341.

A. Ramos, F. Ramos, Strategies in tower solar power plant optimization, Solar Energy 86 (9) (2012) 2536-2548.

C. J. Noone, M. Torrilhon, A. Mitsos, Heliostat field optimization: A new computationally efficient model and biomimetic layout, Solar Energy 86 (2) (2012) 792 - 803, ISSN 0038-092X, doi:\bibinfo\{doi\}\{10.1016/j.solener. 2011.12.007\}, URL http://www.sciencedirect.com/science/article/ pii/S0038092X11004373.

Y. Yao, Y. Hu, S. Gao, Heliostat field layout methodology in central receiver systems based on efficiency-related distribution, Solar Energy 117 (2015) 114 - 124, ISSN 0038-092X, doi:\bibinfo\{doi\}\{http://dx.doi. org/10.1016/j.solener.2015.04.029\}, URL http://www.sciencedirect.com/ science/article/pii/S0038092X15002170.

M. Sánchez, M. Romero, Methodology for generation of heliostat field layout in central receiver systems based on yearly normalized energy surfaces, Solar Energy 80 (7) (2006) 861 - 874, ISSN 0038-092X, doi:〈bibinfo\{doi\}\{DOI:10.1016/j.solener.2005.05.014\}, URL http://www.sciencedirect.com/science/article/B6V50-4GR8M2Y-1/2/ ob004fd4306da5331f9ea67d5d84b610.

O. Farges, J. Bézian, H. Bru, M. E. Hafi, R. Fournier, C. Spiesser, Lifetime integration using Monte Carlo Methods when optimizing the design of concentrated solar power plants, Solar Energy 113 (0) (2015) 57 62, ISSN 0038-092X, doi: bibinfo\{doi\}\{http://dx.doi.org/10.1016/j.solener. 2014.12.027\}, URL http://www.sciencedirect.com/science/article/ $\mathrm{pii} / \mathrm{S} 0038092 \mathrm{X} 14006185$.

J. Kennedy, R. Eberhart, Particle swarm optimization, in: Neural Networks, 1995. Proceedings., IEEE International Conference on, vol. 4, IEEE, 19421948, 1995. 
M. Schmitz, P. Schwarzbözl, R. Buck, R. Pitz-Paal, Assessment of the potential improvement due to multiple apertures in central receiver systems with secondary concentrators, Solar Energy 80 (1) (2006) 111-120.

J. de La Torre, G. Baud, J. Bézian, S. Blanco, C. Caliot, J. Cornet, C. Coustet, J. Dauchet, M. E. Hafi, V. Eymet, R. Fournier, J. Gautrais, O. Gourmel, D. Joseph, N. Meilhac, A. Pajot, M. Paulin, P. Perez, B. Piaud, M. Roger, J. Rolland, F. Veynandt, S. Weitz, Monte Carlo advances and concentrated solar applications, Solar Energy 103 (2014) 653-681, ISSN 0038-092X, doi: bibinfo\{doi\}\{http://dx.doi.org/10.1016/j.solener.2013.02.035\}, URL http: //www.sciencedirect.com/science/article/pii/S0038092X13001448.

E. J. Hoogenboom, Zero-variance Monte Carlo schemes revisited, Nuclear science and engineering 160 (1) (2008) 1-22.

M. Roger, S. Blanco, M. El Hafi, R. Fournier, Monte Carlo Estimates of Domain-Deformation Sensitivities, Phys. Rev. Lett. 95 (2005) 180601, doi: bibinfo\{doi\}\{10.1103/PhysRevLett.95.180601\}, URL http://link.aps . org/doi/10.1103/PhysRevLett.95.180601.

M. Pharr, G. Humphreys, Physically Based Rendering, second edition : from theory to implementation, Morgan Kaufmann Publishers, 2010.

F. M. F. Siala, M. E. Elayeb, Mathematical formulation of a graphical method for a no-blocking heliostat field layout, Renewable energy 23 (1) (2001) 77-92.

M. Roger, M. El Hafi, R. Fournier, S. Blanco, A. De Lataillade, V. Eymet, P. Perez, É. d. M. d. Carmaux, Applications of sensitivity estimations by Monte Carlo methods, in: The 4th International Symposium on Radiative Transfer, 2004.

M. Wetter, J. Wright, A comparison of deterministic and probabilistic optimization algorithms for nonsmooth simulation-based optimization, Building and Environment 39 (8) (2004) 989-999.

R. Osuna, V. Fernández, S. Romero, M. Romero, M. Sanchez, PS10: a 11.0-MW solar tower power plant with saturated steam receiver, in: C. Ramos, J. Huacuz (Eds.), Proceedings 12th SolarPACES International Symposium, 2004 .

R. Osuna, R. Olavarría, R. Rafael Morillo, Construction of a 11MW Solar Thermal Tower Plant in Seville, Spain, in: Proceeding of 13 th Solar PACES Symposium, Seville, Spain, 2006.

N. Blair, A. P. Dobos, J. Freeman, T. Neises, M. Wagner, T. Ferguson, P. Gilman, S. Janzou, System advisor model, sam 2014.1. 14: General description, Tech. Rep., National Renewable Energy Laboratory (NREL), Golden, CO., 2014. 
BrightSource, Ivanpah solar electric generating system, Tech. Rep., BrightSource, URL www.brightsourceenergy.com/stuff/contentmgr/files/ 0/3eac1a9fed7f13fe4006aaab8c088277/attachment/ivanpah_white_ paper_0414.pdf, 2015. 


\section{Nomenclature}

\begin{tabular}{|c|c|c|c|}
\hline \multicolumn{2}{|c|}{ Roman symbols } & \multirow[t]{2}{*}{$\mathcal{R}$} & \multirow{2}{*}{$\begin{array}{l}\text { Receiver (the exponent }+ \text { in- } \\
\text { dicates the active side) }\end{array}$} \\
\hline$A_{H}$ & Area of each heliostat in $\mathrm{m}^{2}$ & & \\
\hline$A_{t}$ & Total area of mirror in $\mathrm{m}^{2}$ & $t$ & Time in $\mathrm{s}$ \\
\hline$c_{1}$ & $\begin{array}{l}\text { Attraction parameter for in- } \\
\text { dividual behaviour of the } \\
\text { particle }\end{array}$ & $\begin{array}{l}T M Y \\
v_{i}^{k}\end{array}$ & $\begin{array}{l}\text { Typical Meteorological Year } \\
\text { Current velocity of the } i \text { par- } \\
\text { ticle at the } k \text { iteration }\end{array}$ \\
\hline$c_{2}$ & $\begin{array}{l}\text { Attraction parameter for so- } \\
\text { cial behaviour of the particle }\end{array}$ & $\begin{array}{l}v_{r} \\
w\end{array}$ & $\begin{array}{l}\text { Receiver vertical shift in } \mathrm{m} \\
\text { Inertia weight }\end{array}$ \\
\hline$d$ & $\begin{array}{l}\text { Distance between both ends } \\
\text { of a sun ray in } m\end{array}$ & $\begin{array}{l}h_{h} \\
w_{h}\end{array}$ & $\begin{array}{l}\text { Heliostat height in } \mathrm{m} \\
\text { Heliostat width in } \mathrm{m}\end{array}$ \\
\hline$D N I$ & $\begin{array}{l}\text { Direct normal irradiance in } \\
\mathrm{W} \mathrm{m}^{-2}\end{array}$ & $\hat{w}_{i}$ & $\begin{array}{l}\text { Monte Carlo weight of the } i \\
\text { variable }\end{array}$ \\
\hline E & $\begin{array}{l}\text { Yearly average energy in } \\
\text { GWh }\end{array}$ & $\begin{array}{l}w_{r} \\
x_{i}^{k}\end{array}$ & $\begin{array}{l}\text { Receiver width in } \mathrm{m} \\
\text { Current position of the } i \text { par- }\end{array}$ \\
\hline$f_{t}$ & Target function & & ticle at the $k$ iteration \\
\hline$g$ & $\begin{array}{l}\text { Global best position of the } \\
\text { swarm }\end{array}$ & $x_{\max }$ & $\begin{array}{l}\text { Maximal position for a par- } \\
\text { ticle }\end{array}$ \\
\hline $\mathcal{H}$ & $\begin{array}{l}\text { Heliostat surface (the expo- } \\
\text { nent }+ \text { indicates the active } \\
\text { side) }\end{array}$ & $\begin{array}{l}x_{\min } \\
\text { Greek }\end{array}$ & $\begin{array}{l}\text { Minimal position for a parti- } \\
\text { cle } \\
\text { symbols }\end{array}$ \\
\hline$H$ & The Heaviside step function & $\alpha_{r}$ & Receiver tilt angle in rad \\
\hline $\begin{array}{l}h_{r} \\
H_{t}\end{array}$ & $\begin{array}{l}\text { Receiver height in } \mathrm{m} \\
\text { Height of the Tower in } \mathrm{m}\end{array}$ & $\eta$ & $\begin{array}{l}\text { Instantaneous heliostat field } \\
\text { optical efficiency }\end{array}$ \\
\hline$k$ & $\begin{array}{l}\text { User-supplied PSO velocity } \\
\text { clamping factor }\end{array}$ & $\eta_{a a}$ & $\begin{array}{l}\text { Atmospheric attenuation } \\
\text { efficiency }\end{array}$ \\
\hline$k_{\max }$ & $\begin{array}{l}\text { Number of iterations per- } \\
\text { formed during PSO run }\end{array}$ & $\begin{array}{l}\eta_{\cos } \\
\eta_{i}\end{array}$ & $\begin{array}{l}\text { Cosine efficiency } \\
\text { Global sun ray efficiency }\end{array}$ \\
\hline$n_{1}$ & Ideal normal at $\boldsymbol{x}_{1}$ & $\eta_{i t c}$ & Interception efficiency \\
\hline $\boldsymbol{n}_{h}$ & $\begin{array}{l}\text { Effective normal at } \boldsymbol{x}_{\boldsymbol{1}} \\
\text { around the ideal normal } \boldsymbol{n}_{\mathbf{1}} \\
\text { Number of MUEEN pattern }\end{array}$ & $\begin{array}{l}\eta_{\text {ray }} \\
\eta_{s b}\end{array}$ & $\begin{array}{l}\text { Sun ray efficiency } \\
\text { Shading and blocking effi- } \\
\text { ciency }\end{array}$ \\
\hline$N_{h}$ & $\begin{array}{l}\text { heliostat group } \\
\text { Number of heliostats in the } \\
\text { field }\end{array}$ & $\eta_{Y}$ & $\begin{array}{l}\text { Yearly heliostat field optical } \\
\text { efficiency } \\
\text { Solar cone in sr }\end{array}$ \\
\hline $\begin{array}{l}N_{r} \\
p_{i}\end{array}$ & $\begin{array}{l}\text { Number of sun rays } \\
\text { Particle } i \text { best position }\end{array}$ & $\omega_{1}$ & $\begin{array}{l}\text { Direction after reflection in } \\
\text { rad }\end{array}$ \\
\hline $\begin{array}{l}P S O \\
\boldsymbol{r}_{j}\end{array}$ & $\begin{array}{l}\text { Particle Swarm Optimizer } \\
\text { Point in the geometry }\end{array}$ & $\boldsymbol{\omega}_{s}$ & $\begin{array}{l}\text { Direction inside the solar } \\
\text { cone in rad }\end{array}$ \\
\hline & Random number $r_{1} \sim U(0,1)$ & & Heliostat reflectivity \\
\hline $\begin{array}{l}r_{2} \\
S P T\end{array}$ & $\begin{array}{l}\text { Random number } r_{2} \sim U(0,1) \\
\text { Solar Power Tower }\end{array}$ & $\sigma_{h}$ & Heliostat optical error \\
\hline
\end{tabular}


Table 1: PS10 characteristics

\begin{tabular}{lc}
\hline Location & Sanlùcar La Mayor \\
Latitude & $37.2^{\circ} \mathrm{N}$ \\
Latitude & $6.25^{\circ} \mathrm{W}$ \\
\hline & \\
\hline Heliostats & \\
Number & 624 \\
Reflectivity $\rho_{h}$ & 0.88 \\
Optical error $\sigma_{h}$ & $2.9 \mathrm{mrad}$ \\
Width $w_{h}$ & $12.84 \mathrm{~m}$ \\
Height $h_{h}$ & $9.45 \mathrm{~m}$ \\
\hline & \\
\hline Receiver & \\
Vertical shift $v_{r}$ & $100.5 \mathrm{~m}$ \\
Tilt angle $\alpha_{r}$ & $12.5^{\circ}$ \\
Width $w_{r}$ & $13.78 \mathrm{~m}$ \\
Height $h_{r}$ & $12 \mathrm{~m}$ \\
\hline
\end{tabular}

Table 2: Lower and upper bounds of parameters

\begin{tabular}{lcccc}
\hline$f_{\boldsymbol{t}}$ & Heliostat parameters & $\begin{array}{c}\text { Lower bound } \\
\mathrm{m}\end{array}$ & $\begin{array}{c}\text { Upper bound } \\
\mathrm{m}\end{array}$ & SPT Ref. \\
\hline$E$ & $w_{h}, h_{h}$ & 0.5 & 6.0 & $A_{1}$ \\
$\eta_{Y}$ & $w_{h}, h_{h}$ & 0.5 & 6.0 & $A_{2}$ \\
$E$ & $w_{h}, h_{h}$ & 3 & 9.0 & $B_{1}$ \\
$\eta_{Y}$ & $w_{h}, h_{h}$ & 3 & 9.0 & $B_{2}$ \\
$E$ & $w_{h}, h_{h}$ & 6.0 & 12.0 & $C_{1}$ \\
$\eta_{Y}$ & $w_{h}, h_{h}$ & 6.0 & 12.0 & $C_{2}$ \\
$E$ & $w_{h}, h_{h}$ & 9.0 & 15.0 & $D_{1}$ \\
$\eta_{Y}$ & $w_{h}, h_{h}$ & 9.0 & 15.0 & $D_{2}$ \\
$E$ & $w_{h}, h_{h}$ & 12.0 & 18.0 & $E_{1}$ \\
$\eta_{Y}$ & $w_{h}, h_{h}$ & 12.0 & 18.0 & $E_{2}$ \\
$E$ & $w_{h}, h_{h}$ & 15.0 & 20.0 & $F_{1}$ \\
$\eta_{Y}$ & $w_{h}, h_{h}$ & 15.0 & 20.0 & $F_{2}$ \\
\hline
\end{tabular}

Table 3: PSO specifications

PSO parameters

Individual behaviour $c_{1} \quad 1$

Social behaviour $c_{2} \quad 1$

Inertia $w \quad 0.6$

Number of particles $\quad 50$

Number of iteration $w \quad 200$ 
Table 4: Comparison of characteristics of redesigned heliostat fields

\begin{tabular}{lccccccc}
\hline SPT Ref. & $\boldsymbol{N}_{\boldsymbol{h}}$ & $\begin{array}{c}\boldsymbol{A}_{\boldsymbol{h}} \\
\mathrm{m}^{2}\end{array}$ & $\begin{array}{c}\boldsymbol{w}_{\boldsymbol{h}} \\
\mathrm{m}\end{array}$ & $\begin{array}{c}\boldsymbol{h}_{\boldsymbol{h}} \\
\mathrm{m}\end{array}$ & $\begin{array}{c}\boldsymbol{A}_{\boldsymbol{t}} \\
\mathrm{m}^{2}\end{array}$ & $\begin{array}{c}\boldsymbol{\Delta}_{\boldsymbol{A}_{\boldsymbol{t}}} \\
\boldsymbol{N}\end{array}$ & $\boldsymbol{N}_{\boldsymbol{G}}$ \\
\hline PS10 & 624 & 121 & 12.84 & 9.45 & 75504 & & \\
\hline$A_{1}$ & 11331 & 8.4 & 3.89 & 2.15 & 94766 & 25.5 & 6 \\
$A_{2}$ & 9461 & 8.4 & 3.07 & 2.74 & 79584 & 5.4 & 7 \\
$B_{1}$ & 3040 & 30.6 & 7.24 & 4.22 & 92880 & 23 & 5 \\
$B_{2}$ & 1618 & 46.9 & 7.24 & 6.49 & 75920 & 0.5 & 5 \\
$C_{1}$ & 1651 & 53.2 & 8.87 & 6 & 87866 & 163 & 5 \\
$C_{2}$ & 1048 & 75 & 9.37 & 8.0 & 78558 & 4 & 5 \\
$D_{1}$ & 705 & 123.2 & 13.02 & 9.46 & 86834 & 15 & 4 \\
$D_{2}$ & 426 & 169.4 & 14.09 & 12.02 & 72148 & -4.4 & 4 \\
$E_{1}$ & 333 & 251 & 17.99 & 13.95 & 83569 & 10.7 & 4 \\
$E_{2}$ & 278 & 254.4 & 16.63 & 15.3 & 70734 & -6.3 & 4 \\
$F_{1}$ & 272 & 295.9 & 18.32 & 16.15 & 80476 & 6.5 & 4 \\
$F_{2}$ & 248 & 291 & 18.49 & 15.74 & 72176 & -4.4 & 4 \\
\hline
\end{tabular}

Table 5: Comparison of performance of redesigned heliostat fields

\begin{tabular}{lcccc}
\hline SPT Ref. & $\begin{array}{c}\boldsymbol{E} \\
\mathrm{GW} \mathrm{h}_{\text {th }}\end{array}$ & $\begin{array}{c}\boldsymbol{\Delta}_{\boldsymbol{E}} \\
\%\end{array}$ & $\boldsymbol{\eta}_{\boldsymbol{Y}}$ & $\begin{array}{c}\boldsymbol{\Delta}_{\boldsymbol{\eta}_{\boldsymbol{Y}}} \\
\%\end{array}$ \\
\hline PS10 & 89.8 & & 0.63 & \\
\hline$A_{1}$ & 110.9 & $\mathbf{2 3 . 5}$ & 0.617 & -2.37 \\
$A_{2}$ & 103.4 & 15.14 & 0.689 & 9.02 \\
$B_{1}$ & 110 & 22.49 & 0.627 & -0.79 \\
$B_{2}$ & 99 & 10.24 & 0.69 & $\mathbf{9 . 1 8}$ \\
$C_{1}$ & 107.2 & 19.38 & 0.647 & 2.37 \\
$C_{2}$ & 101.4 & 12.92 & 0.683 & 8.07 \\
$D_{1}$ & 106.6 & 18.71 & 0.651 & 3.01 \\
$D_{2}$ & 92.9 & 3.45 & 0.68 & 7.59 \\
$E_{1}$ & 103.8 & 15.59 & 0.656 & 3.8 \\
$E_{2}$ & 91.1 & 1.45 & 0.682 & 7.91 \\
$F_{1}$ & 101 & 12.47 & 0.66 & 4.43 \\
$F_{2}$ & 92.8 & 3.34 & 0.68 & 7.59 \\
\hline
\end{tabular}

